\title{
CASAMENTO E AMOR
}

Marriage And Love

AUTORA: EMMA GOLDMAN TRADUTOR: JOSÉ PAULO MALDONADO DE SOUZA²

RESUMO: O ensaio Casamento e Amor, de Emma Goldman (1869-1940), originalmente publicado em Anarchism and Other Essays (1910), discute a relação do casamento e do amor como fatores de companheirismo e união numa ótica anarquista.

Palavras-Chave: Amor livre; feminilidade; sexo.

ABSTRACT: Emma Goldman's (1869-1940) essay Marriage and Love, originally published in Anarchism and Other Essays (1910), discusses the relationship of marriage and love as factors of fellowship and unity in an anarchist perspective.

Keywords: Free love; femininity; sex.

A noção popular em torno do casamento e do amor é a de que sejam sinônimos, que afloram das mesmas razões e preenchem as mesmas carências humanas. Como tantas outras noções populares, também esta não repousa em fatos concretos, mas sob superstições.

Casamento e amor não possuem nada em comum; são tão apartados como polos opostos; e são, com efeito, antagônicos entre si. Sem dúvidas que certos casamentos são resultado do amor. Entretanto, não por que o amor só se afirma em casamento; mas por que poucas pessoas são capazes de superar completamente uma convenção. Hoje, para um grande número de homens e mulheres, o casamento nada é senão uma farsa, mas a ele se submetem por amor à opinião pública. Em todo caso, enquanto é verdade que certos casamentos fundam-se no amor e igualmente verdade que certas vezes o amor perdura na vida conjugal, eu sustento que isso se dá independentemente do casamento e não devido a ele.

Por outro lado, é inteiramente falso que o amor possa ser resultado do casamento. Um caso milagroso se faz ouvir, em raras ocasiões, de cônjuges que se apaixonaram depois de casados, mas um exame minuncioso revelaria aí um mero ajuste ao inevitável. Certamente, a

\footnotetext{
${ }^{1}$ N.T.: Texto original em domínio público. GOLDMAN, Emma. "Marriage and love". In: Anarchism and Other Essays. New York-London: Mother Earth Publishing Association, 1911.

2 Mestre em Filosofia pelo Programa de Pós Graduação em Filosofia da UFPE.
} 
habituação mútua não teria a mesma espontaneidade, intensidade e beatitude do amor, sem as quais a intimidade do casamento revelar-se-ia degradante para ambos o homem e a mulher.

O casamento é em primeiro lugar um arranjo econômico, um contrato de seguro. Só difere do contrato comum justamente naquilo que este tem de mais compulsório, de mais exigente. Os retornos são insignificantemente pequenos se comparados aos investimentos. Quando contratamos uma apólice de seguro, pagamos por ela em dólares e centavos, mas sempre nos resta a liberdade de descontinuar os pagamentos. Contudo, se o prêmio do seguro for o marido, a mulher pagará com seu nome, com sua privacidade, com sua autoestima e com sua própria vida "até que a morte os separe". Além do que, o contrato do casamento condena-a a uma dependência vitalícia, ao parasitismo, à mais completa inutilidade individual bem como social. $\mathrm{O}$ homem também paga a sua quota, mas como sua esfera é mais ampla, o casamento não o limita tanto quanto a mulher. Ele sente suas correntes pesarem num sentido mais econômico.

E assim o mote do Inferno de Dante se aplica ao casamento com a mesma força: "Deixai toda esperança, ó vós que entrais!".

Somente alguém completamente estúpido negaria que o casamento é um fracasso. Basta relancear a vista sobre as estatísticas do divórcio para perceber como é amargo o fracasso do casamento. Tampouco o estereotipado argumento filisteu, à saber, o da crescente lassidão da mulher e das leis do divórcio, será capaz de explicar o fato de que: em primeiro lugar, a cada décimo segundo casamento um termina em divórcio; segundo, que desde 1870, os divórcios cresceram de 28 para 73 a cada população de 300; terceiro, que desde 1867, o adultério como causa do divórcio cresceu 280,7\%; quarto, que a deserção aumentou em 369,8\%.

Somado a estes números surpreendentes, há ainda um vasto material dramático e literário melhor elucidando o assunto. Robert Herrick, em Together; Pinero, em Mid-Channel; Eugene Walter, em Paid in Full, e dezenas de outros escritores estão discutindo a aridez, a monotonia, a sordidez, e a inadequação do casamento como um fator de harmonia e entendimento.

O estudioso social sério não se contentará com a superficial desculpa popular dada a este fenômeno. Ele terá de escavar a vida dos sexos profundamente adentro para compreender o porquê de o casamento revelar-se tão desastroso.

Edward Carpenter diz que por trás de todo casamento persiste uma ambiência vitalícia dos dois sexos; ambiências tão distintas entre si que marido e mulher devem permanecer estranhos um ao outro. Separados por uma intransponível muralha de superstição, costume e hábito, o casamento não teria a potencialidade de desenvolver o conhecimento e o respeito mútuo, sem os quais toda união estaria fadada ao fracasso. 
Henrik Ibsen ${ }^{1}$, inimigo de toda farsa social, provavelmente foi o primeiro a conceber esta grande verdade. Nora ${ }^{2}$ abandonou o marido, não por que - como queria a crítica estúpida havia se cansado de suas responsabilidades ou reclamava os direitos da mulher, mas por que chegou a conclusão de que durante oito anos convivera com um estranho e agora havia dado à luz um filho seu. Pode existir algo mais humilhante, mais degradante, do que a proximidade vitalícia entre dois estranhos? Não é preciso que a mulher saiba nada sobre o homem, exceto sua renda. Quanto à mulher - o que é preciso saber, exceto se possui boa aparência? Não superamos ainda o velho mito teológico em que a mulher não tem alma, em que ela é um mero apêndice do homem, feita de sua costela para sua conveniência.

Por ventura do material de parca qualidade, a mulher tornou-se responsável pela própria inferioridade. Em todo caso, a mulher não tem alma - existe algo nela para ser conhecido? Além do que, quanto menos alma possui a mulher, maior sua vocação para esposa, o mais prontamente absorver-se-á ao marido. É essa servil aquiescência à superioridade do homem que manteve por tão longo tempo a instituição do casamento aparentemente intacta. Mas agora que a mulher está dando conta de si, agora que ela está cada vez mais consciente de si mesma como um ser exterior à graça do mestre, a sagrada instituição do casamento está gradualmente ruindo, e nenhum lamento emocional pode mais evitá-lo.

Desde a mais tenra infância é ensinado à garota que seu objetivo final é o casamento; portanto todo seu treino e educação devem ser direcionados para este fim. Como a besta muda na engorda, ela é conduzida para o abate. Mas, por incrível que pareça, ao contrário do trabalhador comum, nada lhe é permitido saber sobre sua futura função de esposa e mãe. Para uma garota respeitável, é indecente e sujo saber qualquer coisa a respeito da relação conjugal. Ah! Pela incoerência da respeitabilidade, exigir votos de casamento para tornar algo sujo no mais puro e sagrado arranjo, que ninguém ousaria questionar ou criticar. No entanto, é exatamente esta a atitude do entusiasta comum do casamento. A futura esposa e mãe é mantida na mais completa ignorância em relação a sua única inclinação no campo competitivo — o sexo. Desse modo, ela entra numa relação vitalícia com um homem, na qual certamente ver-se-á chocada, repelida, e ultrajada além da medida, apenas devido ao seu mais natural e saudável instinto, o sexo. É seguro dizer que uma grande percentagem de infelicidade, miséria, aflição, e sofrimento físico do matrimônio decorra da ignorância criminosa em matéria de sexo que é exortada por muitos como uma grande virtude. Tampouco é um exagero quando digo que devido a este fato deplorável mais de um lar foi desfeito.

\footnotetext{
${ }^{1}$ N.T.: Henrik Ibsen (1828-1906), dramaturgo escandinavo conhecido por sua tendência anarquista-individualista. A autora faz uma crítica mais demorada da obra de Ibsen no livro The Social Significance of the Modern Drama (1914). 2 N.T.: Nora é personagem da peça Et dukkehjem (1879), traduzido em inglês como A Doll's House, de Ibsen.
} 
Entretanto, se a mulher for grande e livre o bastante para conhecer o mistério do sexo sem a sanção do Estado ou da Igreja, ela será julgada como absolutamente imprópria para desposar um "bom" homem, sua bondade consistindo num cérebro vazio e num bolso cheio. Pode existir algo mais ultrajante que a ideia de uma mulher saudável, em plena idade, cheia de paixão e vida, dever negar as demandas da natureza, reprimir o seu mais intenso desejo, prejudicar a sua saúde, quebrantar o seu espírito, cegar a própria vista, abster-se de toda a glória e de toda profundidade da experiência do sexo, até que eis que lhe apareça um "bom" homem para tomá-la como legítima esposa? É precisamente isso que significa o casamento. Como poderia tal arranjo terminar senão em fracasso? Estes são alguns fatores, não menos importantes, que diferenciam o casamento do amor.

A nossa era é uma era prática. O tempo em que Romeu e Julieta arriscaram-se à fúria dos pais por amor, em que Gretchen expôs-se aos seus concidadãos por amor, acabou. Se, em raras ocasiões, os jovens ainda se permitem a luxúria do romance, prontamente os mais velhos tratam de pregá-los e martelá-los até recobrarem a "sensatez".

A lição moral instilada na garota não é a de se o homem é ou não capaz de arrebatar o seu amor, porém, o "Quanto?". O único e mais importante Deus da vida prática americana: Conseguirá este homem ganhar a vida? Conseguirá ele sustentar uma esposa? Esta é a única coisa que justifica o casamento. Isso tudo gradualmente satura o pensamento da garota, que então já não mais sonha com beijos à luz da lua, sorrisos e lágrimas; seus únicos sonhos agora são compras e bons negócios. Tal pobreza e sordidez da alma são elementos inerentes à instituição do casamento. A única razão pela qual o Estado e a Igreja aprovam este ideal e não outro é simplesmente por que este é o ideal que requer o controle do Estado e da Igreja sobre a vida dos homens e mulheres.

Indubitavelmente ainda existem pessoas que consideram o amor superior a dólares e centavos. E isso é particularmente verdade para a classe daqueles cuja necessidade econômica forçou a que se autossustentassem. A tremenda mudança na posição da mulher operada por este poderoso fator é, de fato, fenomenal quando refletimos que há apenas um curto período do ingresso da mulher na arena industrial. Seis milhões de trabalhadoras assalariadas; seis milhões de mulheres com os mesmos direitos dos homens; direito de ser explorada, roubada e direito de declarar greve; e o pior, o mesmo direito de passar fome. Mais alguma coisa, senhor? Sim, seis milhões de trabalhadoras nos mais diversos postos, dos mais elevados trabalhos intelectuais às minas e ferrovias, inclusive entre detetives e policiais. Certamente, a emancipação é completa.

Apesar disso tudo, só um número muito pequeno do vasto exército de trabalhadoras enxerga o seu trabalho como situação permanente na mesma luz que um homem o faz. Não 
importa quão decrépito este último o seja, ele foi ensinado a ser independente, a se autossustentar. Ah! Mas ninguém é realmente independente em nosso moinho econômico; assim mesmo, o mais miserável espécime de homem odiaria ser um parasita ou, pelo menos, ser reconhecido como tal.

A mulher considera sua situação de trabalhadora transitória, prestes a ser largada com o aparecimento do primeiro pretendente. Este é o porquê de ser infinitamente mais difícil organizar mulheres do que homens. "Por que me filiar a um sindicato? Vou me casar, ter um lar". Desde a infância não the foi ensinado a enxergar isso como sua convocação última? Mas ela prontamente descobre que apesar de não tão espaçosa quanto a prisão da fábrica, o lar possui grades e portões ainda mais férreos. E um guarda tão fiel a qual nada pode passar despercebido. E a parte mais trágica, contudo, é que o lar não a liberta da escravidão assalariada; apenas redobra seus afazeres.

De acordo com as mais recentes estatísticas submetidas ao Comitê "à propósito do trabalho, salários e congestão da população", só em Nova York, 10\% das assalariadas são casadas, ainda que continuem nos trabalhos mais mal remunerados do mundo. Some a essa visão horrível o peso do serviço doméstico e diga-me agora o que resta de toda a proteção e glória do lar? Como matéria de fato, nem a garota classe média pode falar de um lar no casamento, desde que é o homem que cria sua esfera. Aqui não é tão importante se o marido é carinhoso ou grosseiro. O que desejo mostrar é que o casamento só garante um lar à mulher graças ao marido. Ela gira em torno do lar dele, ano após ano, até que sua visão de mundo e relações humanas torne-se tão rasa, tão estreita e entediante quanto seu entorno. Pouco admira se ela se torna reclamona, trivial, briguenta, fofoqueira, insuportável, desse modo, espantando o homem da casa. Mesmo se ela quisesse, não poderia partir; pois não há para onde ir. Além do que, um curto prazo de vida conjugal, da mais completa rendição de todas as faculdades, incapacita totalmente a mulher para o mundo exterior. Ela se torna indiferente à aparência, desajeitada em seus movimentos, dependente em suas decisões, covarde em seus julgamentos, um verdadeiro fardo e um aborrecimento cuja maioria dos homens estão acostumados a odiar e a desprezar. Mas que atmosfera magicamente inspiradora para o desenrolar da vida, não é mesmo?

Mas e a criança, como será protegida sem o casamento? Afinal de contas, não é esta a consideração mais importante? Quanta farsa, quanta hipocrisia! O casamento protege a criança, mas temos milhares de crianças abandonadas. O casamento protege a criança, mas nossos orfanatos e reformatórios estão lotados, e a Sociedade pela Prevenção de Crueldade a Criança ${ }^{1}$ sempre ocupada no resgate das pequenas vítimas dos cuidados "amorosos" dos seus pais, no entanto,

1 N.T.: Referência a New York Society for the Prevention of Cruelty to Children, a primeira instituição dedicada à "proteção do menor" nos E.U.A., em atividade desde 1874. Gerry Society é apenas outro modo de referir-se à mesma instituição. 
não pode mais do que confiá-las aos cuidados ainda mais amorosos da Gerry Society. Ah! Mas que piada!

O casamento pode até levar o cavalo à água, mas conseguirá obrigá-lo a beber? A lei pode levar o pai à detenção, trajá-lo com uniforme penitenciário; mas alguma vez já foi capaz de matar a fome do filho? Se o pai não tem emprego ou se oculta a identidade, que faz, então, o casamento? Invoca a lei para levá-lo a "justiça”, prendê-lo em segurança atrás das grades; seu trabalho ${ }^{1}$, entretanto, não segue para a criança, mas para o Estado. A criança só recebe uma lembrança enferrujada das listras de seu pai.

Com relação à proteção da mulher — aqui reside a verdadeira maldição do casamento. Ele não a protege, em absoluto, e essa ideia mesma é tão revoltante quanto um ultraje ou um insulto à vida, tamanha degradação que o casamento inflige à dignidade humana é suficiente para condená-lo eternamente como uma instituição parasitária.

Tal como aquele outro arranjo paternalista - o capitalismo. Rouba do homem os seus direitos, atrapalha o seu crescimento, envenena o seu corpo, submete-o à ignorância, à pobreza, à dependência, e eis então que aparece promovendo caridades que florescem sobre os últimos vestígios do autorrespeito humano.

A instituição do casamento transforma a mulher numa completa parasita, uma dependente absoluta. Incapacita-a para a luta da vida, aniquila sua consciência social, paralisa sua imaginação, e eis então que aparece para conceder sua graciosa proteção, que na verdade é um ardil.

Se a maternidade é a mais elevada realização da natureza da mulher, que outra proteção precisaria além de amor e liberdade? O casamento só contamina, ultraja, e corrompe esta realização. Não é ele quem diz à mulher: darás à luz somente se me seguires? Não é ele quem degrada e humilha a mulher quando ela se recusa a vender junto consigo seu direito à maternidade? Não é o casamento apenas a sanção da maternidade, ainda que a criança seja concebida em ódio, em compulsão? Mas quando a maternidade é fruto da livre escolha, do amor, do êxtase, da paixão desafiante, não é ele mesmo, o casamento, que vêm de cravar uma coroa de espinhos numa efígie inocente, e grafar-lhe em letras de sangue o hediondo epíteto de Bastardo? Ainda que o casamento contivesse todas as virtudes alegadas, seus crimes contra a maternidade bastariam para excluí-lo eternamente do reino do amor.

Amor, o mais forte e profundo elemento de toda a vida, o mensageiro da esperança, da alegria, do êxtase; amor, o contestador de todas as leis, de todas as convenções; amor, o libérrimo

1Referência à prática de trabalho forçado nas penitenciárias dos E.U.A. 
e poderosíssimo modelador do destino humano; como pode uma força toda poderosa ser sinônima do casamento, qual pobre erva daninha cultivada pelo Estado e a Igreja?

Amor livre? Como se o amor pudesse não ser livre! O homem comprou cérebros, mas todos os cérebros do mundo foram incapazes de comprar o amor. O homem subjugou corpos, mas nenhum poder sobre a terra foi capaz de subjugar o amor. O homem conquistou nações inteiras, mas nenhum exército do mundo jamais conseguiu conquistar o amor. O homem agrilhoou e acorrentou o espírito, mas diante do amor sucumbe absolutamente indefeso. Do alto dos tronos, diante de todo o esplendor e glória que o ouro pode comandar, pobre e desolado ainda é o homem que não conhece o amor. Mas quando o amor acontece, o casebre mais pobre é capaz de irradiar calor, cor e vida. E dessa forma, o amor possui o poder mágico de transformar um mendigo num rei. Sim, o amor é livre; não pode habitar outra atmosfera. Em liberdade doa-se sem reservas, abundantemente, completamente. Todas as leis nos estatutos, todos os tribunais do universo, não são capazes de extraí-lo da terra, uma vez que tenha fincado raízes. Contudo, se o solo é estéril, como poderia o casamento torná-lo fértil? Seria como a última batalha desesperada da vida contra a morte.

O amor não precisa de proteção; ele é sua própria proteção. Tão logo vidas sejam geradas pelo amor, nenhuma criança será desertada, passará fome ou carência afetiva. Que isto é verdade, bem o sei. Conheço mulheres que se tornaram mães em liberdade dos homens que amaram. Poucas crianças na relação gozam de todo cuidado, proteção e devoção que a maternidade livre é capaz de conceder.

Os defensores da autoridade temem o advento da maternidade livre, com receio de que ela subtraia-lhe as presas. Quem combateria nas guerras? Quem produziria as riquezas? Quem faria o papel do policial, do carcereiro, se a mulher se recusasse a reprodução indiscriminada de crianças? A raça, a raça! - grita o rei, o presidente, o capitalista, o padre. A raça deve ser preservada, mas a mulher degradada à mera máquina - e a instituição do casamento é nossa única válvula de segurança contra o pernicioso despertar sexual da mulher. No entanto, todos os frenéticos esforços para perpetuar este estado de sujeição foram em vão. Como em vão também o foram todos os éditos da Igreja, todos os ensandecidos ataques dos governantes, até mesmo dos braços da lei, tudo isso foi em vão. A mulher não deseja mais participar da reprodução de uma raça de seres humanos doentios, débeis, decrépitos, miseráveis, que não possuem nem a coragem nem a força moral para se libertarem do jugo de pobreza e escravidão de suas vidas. Pelo contrário, almeja poucos filhos, mas filhos superiores, gerados e criados pelo amor e a livre escolha; e não por obrigação, como imputa o casamento. Nossos falsos moralistas ainda têm de aprender sobre o profundo senso de responsabilidade com a criança despertado no seio da 
mulher pelo amor em liberdade. É preferível renunciar para sempre a glória da maternidade do que dar à luz numa atmosfera em que se respira apenas destruição e morte. E se porventura ela tornar-se mãe, será para dar à criança o melhor e mais profundo que o seu ser pode oferecer. Crescer com a criança é o seu lema; e ela sabe que somente assim será capaz de construir a verdadeira masculinidade e a verdadeira feminilidade.

Ibsen deve ter vislumbrado uma mãe livre quando, num golpe de mestre, retratou Ms. Alving ${ }^{1}$. Ela foi uma mãe ideal, porque superou o casamento e todos os seus horrores, porque rompeu suas correntes e libertou o seu espírito para voar, até recobrar uma personalidade forte e regenerada. Ob! Mas já era tarde demais para recuperar sua alegria de viver, seu Oswald; mas não tarde demais para compreender que o amor em liberdade é o único requisito de uma vida bela. Aquelas que como Ms. Alving pagaram com sangue e lágrimas o preço do despertar espiritual, repudiam o casamento como uma imposição e uma piada de baixo nível, absolutamente sem graça. Elas sabem que apenas o amor, quer dure um breve espaço de tempo quer dure pela eternidade, é a única base criativa, inspiradora e elevada para uma nova raça e um novo mundo.

Em nosso presente estado pigmeu, para a maioria das pessoas o amor é, de fato, um estranho. Incompreendido e evitado, o amor raramente lança raízes, e quando insiste, prontamente seca e murcha. Suas delicadas fibras não suportam a tensão maçante do cotidiano. Sua alma é demasiadamente complexa para ajustar-se à trama viscosa do nosso tecido social. Ele sofre, chora e lamenta por todos aqueles que dele carecem, mas são incapazes de aceder aos cumes do amor.

Um dia... homens e mulheres alcançarão o pico da montanha, onde se encontrarão grandes, fortes e livres, totalmente prontos para receber, partilhar e refestelar-se nos raios dourados do amor. Que fantasia, que imaginação, que gênio poético, poderia entrever, ainda que aproximadamente, as potencialidades de tal força na vida de homens e mulheres. Se porventura o mundo der à luz ao verdadeiro companheirismo e união, não será o casamento, mas o amor a concebê-los.

1 Ms. Alving ou Srta. Alving é a protagonista da peça Gengangere (1881), traduzido em inglês como Ghosts, de Ibsen. 